\section{EDUCACÃ̃O}

V.8 • N.3 • Publicação Contínua - 2020

ISSN Digital: 2316-3828

ISSN Impresso: 2316-333X

DOI: 10.17564/2316-3828.2020v8n3p378-392
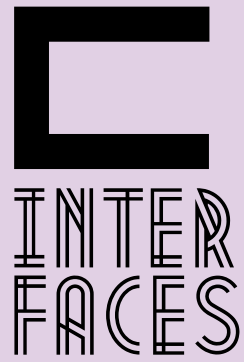

CIENTÍFICAS

\title{
RELEVÂNCIA E LIMITAÇÕES DO ENSINO DO MANDARIM EM PORTUGAL: UMA BREVE ANÁLISE ${ }^{1}$
}

PERTINENCIA Y LIMITACIONES DE LA ENSEÑANZA DE MANDARINA EN PORTUGAL: BREVE ANÁLISIS

\section{RELEVANCE AND LIMITATIONS OF THE TEACHING} OF MANDARIN IN PORTUGAL: A BRIEF ANALYSIS

Yuxiong Zhang ${ }^{2}$ António Moreira ${ }^{3}$

1 This article reports research developed within the PhD Program Technology Enhanced Learning and Societal Challenges, funded by Fundação para a Ciência e Tecnologia, FCTI. P. - Portugal, under contract \# PD/00173/2014.

\section{RESUMO}

0 presente estudo tem como principal escopo evidenciar a importância e as limitações existentes no ensino do Mandarim em Portugal com base num estudo específico referente aos estudantes do segundo ano do curso de Línguas e Relações Empresariais da Universidade de Aveiro. À visto disso, um questionário elementar foi aplicado com os objetivos principais de conceber o motivo de aprendizagem dos estudantes, investigar a possibilidade do uso da língua-alvo na sua rotina quotidiana e compreender a sua consciência do uso de múltiplas estratégias. Os resultados indicaram que o domínio do Mandarim é importante para a empregabilidade em Portugal no contexto de hoje. Contudo, a sua aprendizagem ainda se mantém na memorização da gramática e caracteres e muitos estudantes não estão conscientes da importância do uso da língua-alvo no contexto social, relevando, portanto, a necessidade de prestar atenção à criação das competências orais no ensino e inovação dos materiais didáticos.

\section{PALAVRAS-CHAVE}

Ensino de Línguas Estrangeiras. Ensino de Mandarim. Motivo de Aprendizagem. Relação Sino-portuguesa. 


\section{ABSTRACT}

The main purpose of this article is to highlight the importance and the limitations of teaching Mandarin in Portugal based on a specific study about the sophomores of the course Languages and Business Relations of University of Aveiro. To do so, an elemental questionnaire was applied with the main objectives to understand the students' learning motive, investigate the possibility of using the target language in their daily life and comprehend their conscience of using multiple strategies. The results indicated that nowadays the proficiency in Mandarin is important for the employability in Portugal. Nevertheless, Mandarin learning still remain in memorizing of grammar and characters and many students don't realize the importance of using the target language in social context, which addresses the need of attention on the creation of the speaking skills and innovation of the teaching materials.

\section{KEYWORDS}

Foreign Languages Teaching. Mandarin Teaching, Learning Motive. Sino-Portuguese Relation

\section{RESUMEN}

El objetivo principal de este artículo es resaltar la importancia y las limitaciones de la enseñanza del mandarín en Portugal sobre la base de un estudio específico sobre los estudiantes de segundo año del curso Idiomas y Relaciones Comerciales de la Universidad de Aveiro. Para hacerlo, se aplicó un cuestionario elemental con los objetivos principales para comprender el motivo de aprendizaje de los estudiantes, investigar la posibilidad de usar el idioma de destino en su vida diaria y comprender su conciencia de usar múltiples estrategias. Los resultados indicaron que hoy en día la competencia en mandarín es importante para la empleabilidad en Portugal. Sin embargo, el aprendizaje del mandarín aún permanece en la memorización de la gramática y los caracteres, y muchos estudiantes no se dan cuenta de la importancia de usar el idioma de destino en el contexto social, lo que aborda la necesidad de prestar atención a la creación de habilidades para hablar y la innovación de los materiales de enseñanza.

\section{PALABRAS CLAVE}

Enseñanza de lenguas extranjeras. Enseñanza del mandarín, motivo de aprendizaje. Relación chino-portuguesa 


\section{INTRODUCÇÃO}

Sob o contexto mundial da globalização hoje em dia e do aprofundamento da cooperação entre Portugal e a China nos domínios económico, cultural, científico e tecnológico, entre outros, a comunicação entre dois países torna-se mais frequente e aprofunda-se a um ritmo considerável. Em conformidade com as próprias palavras do Presidente chinês Xi Jinping (2018):

Com o estabelecimento em 2005 da Parceria Estratégica Global, os dois países mantêm contactos frequentes de alto nível, confiança política mútua constantemente aprofundada e cooperação pragmática com resultados frutíferos em todas as áreas. A amizade e a cooperação sino-portuguesas já estão numa via expressa do desenvolvimento.

À vista disso, o domínio de Mandarim, a língua oficial da China passa, neste caso, a desempenhar o papel de "uma mais-valia no currículo escolar e uma vantagem no atual competitivo mercado de trabalho e também dado à sua raridade" (MOUTA, 2015, p. 28). Graças ao apoio robusto dos governos chinês e português, nos anos recentes estabeleceram-se em Portugal quatro Institutos Confúcio (I.C.) - a organização educacional ligada ao Ministério da Educação Chinês com o objetivo de promover a língua e cultura chinesas (I.C. da Universidade do Minho em 2005, I.C. da Universidade de Lisboa em 2008, I.C. da Universidade de Aveiro em 2015, I.C. da Universidade de Coimbra em 2016) (MOUTA, 2015).

Além disso, um número crescente de escolas portuguesas também começou a oferecer cursos de Mandarim nos últimos anos (LUSA, 2016). Pode-se, portanto, dizer que existe em Portugal um ambiente bastante positivo relativamente ao ensino do Mandarim. No entanto, devido à dificuldade intrínseca da língua (CARDOSO, 2014; TOVAR, 2015; DAI; MIAO, 2008), à inadequação dos manuais em relação à situação prática de Portugal (MENDES, 2016), ao tempo limitado de treinamento na sala de aula e ao choque, tanto ao nível da cultura como do modelo de educação entre os dois países, o ensino do Mandarim como Língua Estrangeira está, de facto, a enfrentar muitos desafios.

Segundo a experiência pessoal do ensino do Mandarim em Portugal, bastantes aprendentes manifestam dificuldades em memorizar os caracteres e em compreender a gramática que difere radicalmente da sua língua materna e um certo número deles desiste a meio por causa disso, mesmo que o interesse demonstrado inicialmente seja bastante grande. Por outro lado, segundo o feedback dado pelos alunos, tanto nas aulas como em conversas em privado, para a maioria deles o único material de aprendizagem é o manual que utilizam na aula.

Na verdade, as informações contidas no livro são limitadas e muitas vezes não muito práticas relativamente à utilização na ocasião real que não revela o caráter contextualizado de comunicação (WONG et al., 2017). No entanto, os manuais, que atual e amplamente se utilizam na prática didática não corresponde efetivamente à situação factual de Portugal (MENDES, 2016). Uma grande parte deles é traduzida diretamente de livros em Inglês e, de modo geral, não contêm uma explicação explícita no concernente aos fenômenos gramaticais da língua chinesa. 
Aliás, além do tempo restrito de treinamento na sala de aula, os aprendentes dificilmente podem contatar com o ambiente natural da língua-alvo que também é considerado como uma grande desvantagem intrínseca do ensino de língua estrangeira (YEN et al., 2013; WONG et al., 2016). Contudo, também não se pode omitir completamente a existência de oportunidades para utilizar o Mandarim na vida quotidiana especialmente sob o contexto do frequente intercâmbio cultural devido à globalização e dominação econômica da China no âmbito mundial hoje em dia.

Diante disso, os objetivos principais da presente investigação serão conceber a possibilidade do uso do Mandarim na rotina diária dos aprendentes portugueses e compreender as suas estratégias de aprendizagem preferidas na prática, ou, por outras palavras, as estratégias que os estudantes consideram mais apropriadas para aprender Mandarim com a intenção de tentar perceber a sua consciência de utilizar estratégias na aprendizagem. Ademais, consideramos que também é importante perceber o motivo principal dos estudantes para aprender o Mandarim que, em grande medida, determina o resultado de aprendizagem.

\section{METODOLOGIA}

Neste caso, a fim de perceber a importância de aprendizagem do Mandarim dos estudantes de Portugal e as suas limitações no âmbito do ensino, três questões serão estudadas, designadamente, o motivo de aprendizagem, a possibilidade do uso da língua-alvo na vida quotidiana e a consciência do uso de estratégia. Por esse efeito, focalizaremos a investigação nos estudantes do segundo ano da disciplina de Chinês do curso de Línguas e Relações Empresariais (LRE) da Universidade de Aveiro, a primeira instituição superior que abriu curso relativo à língua chinesa em Portugal (MAI, 2012), apresentando, portanto, um estudo de caso específico.

Dentre as técnicas de recolha dos dados, questionários e entrevistas são duas formas peculiares que permitem obter opiniões subjetivas dos inqueridos que estão "dentro da sua cabeça", possibilitando a medição de informação, conhecimento, preferências, atitudes e crenças (TUCKMAN, 2002, p. 307). Tomando em conta a finalidade do presente estudo, optamos por aplicar um questionário elementar que consiste principalmente em quatro partes, nomeadamente os dados básicos dos entrevistados, o motivo de aprender Mandarim, seu uso possível no quotidiano e estratégias de aprendizagem.

Na primeira parte, três tipos de dados são recolhidos, designadamente, o nome, género e idade. Para garantir a adquisição de mais informações, optamos por aplicar perguntas abertas na segunda e terceira parte que podem trazer informações ricas, detalhadas e, às vezes, inesperadas (HILL; HILL, 1998). E, no entanto, a fim de facilitar o preenchimento e obter mais cooperação dos inquiridos, fornecemos escolhas múltiplas para as três perguntas após a discussão com a docente do curso. No entanto, considerando a restrição que as opções oferecidas podem possuir, disponibilizamos também um espaço para os inquiridos poderem dar resposta livre. 


\section{APRESENTAÇÃO E DISCUSSÃO DOS RESULTADOS}

No total, 30 respostas foram recolhidas. Dentre os inquiridos, três são do sexo masculino e os restantes do sexo feminino. A idade dos entrevistados varia de 19 a 28 anos, com uma média de 20.07 anos e a maior parte deles (14 indivíduos) tem 19 anos.

Na primeira pergunta do inquérito, averiguámos o motivo de aprendizagem do Mandarim dos aprendentes mediante uma pergunta direta - "o que o/a motivou a aprender Mandarim?" Consoante fatores possíveis, fornecemos algumas opções de resposta, designadamente "encontrar emprego", "gostar da cultura (música, cinema, séries etc.) chinesa”, "gostar de aprender línguas”, "considerar que, dentre as três opções de línguas estrangeiras (Russo, Árabe e Mandarim) do curso de LRE, o Mandarim é mais fácil" e "gostar de desafios". No entanto, também considerámos a existência possível de outras motivações e disponibilizamos, por isso, uma opção de resposta aberta.

De acordo com as respostas (TABELA 1), o gosto de aprender línguas é na verdade a motivação da maioria dos aprendentes do Mandarim (vinte e cinco indivíduos). Quinze entrevistados, designadamente, metade dos inqueridos acreditam que o domínio do Mandarim pode ajudar à procura de emprego e isto é, com efeito, o seu motivo principal de aprendizagem que corresponde efetivamente à necessidade do mercado de trabalho atual (MOUTA, 2015).

Aliás, outro inquirido aprende o Mandarim não por causa de nenhuma das possibilidades que referimos, mas porque acredita que o Mandarim será a mais útil para a sua carreira futura dentre as três opções de línguas estrangeiras do seu curso, manifestando também, de certa forma, a importância da língua chinesa nos dias de hoje. E quinze entrevistados aprendem o Mandarim pelo motivo do seu gosto por desafios e dez escolheram aprender a língua chinesa em virtude da sua paixão pela cultura chinesa.

Porém, só um estudante decidiu aprender o Mandarim dado que considera que a língua chinesa é uma língua relativamente mais fácil do que outras unidades curriculares opcionais. Entretanto, o seu sistema fundamentalmente diferente do da língua portuguesa, na verdade, também pode suscitar a curiosidade de aprender o Mandarim. Por exemplo, um estudante escreveu que a complexidade e o sistema de caracteres atraem o seu interesse de aprendizagem.

Por outro lado, sendo semelhante ao abecedário kanji, a aprendizagem dos caracteres chineses pode ser relativamente fácil para quem já domina a língua japonesa, tal como outro inquirido esclareceu no questionário. Neste contexto, se consideramos a necessidade profissional e o próprio interesse em conhecer a cultura e língua chinesas como os motivos pertinentes de aprendizagem, um sexto dos entrevistados aprendem o Mandarim por causa da opção passiva e de má vontade devido à obrigatoriedade do currículo ou por motivo da busca de desafios enquanto três colheram aprender esta disciplina simplesmente pelo seu gosto por aprender línguas. 
Tabela 1 - Respostas da parte de motivo do inquérito

\begin{tabular}{|c|c|c|c|c|c|c|}
\hline & $\begin{array}{l}\text { Encontrar } \\
\text { emprego }\end{array}$ & $\begin{array}{l}\text { Gostar da } \\
\text { cultura (música, } \\
\text { cinema, séries, } \\
\text { etc.) Chinesa }\end{array}$ & $\begin{array}{l}\text { Gostar de } \\
\text { aprender } \\
\text { linguas }\end{array}$ & $\begin{array}{l}\text { Considerar que, dentre as três } \\
\text { opçōes de linguas estrangeiras } \\
\text { (russo, àrabe e mandarim) do curso } \\
\text { de LRE, o mandarim é mais fácil }\end{array}$ & $\begin{array}{l}\text { Gostar } \\
\text { de } \\
\text { desafios }\end{array}$ & Outras razőes \\
\hline 1 & $\operatorname{sim}$ & $\operatorname{sim}$ & $\sin$ & & & \\
\hline 2 & $\operatorname{sim}$ & sim & $\sin$ & & sim & \\
\hline 3 & $\operatorname{sim}$ & $\operatorname{sim}$ & $\operatorname{sim}$ & & & \\
\hline 4 & $\operatorname{sim}$ & & $\sin$ & & $\operatorname{sim}$ & \\
\hline 5 & & sim & $\sin$ & & $\operatorname{sim}$ & \\
\hline 6 & & & $\sin$ & & $\operatorname{sim}$ & \\
\hline 7 & & $\operatorname{sim}$ & $\sin$ & & sim & \\
\hline 8 & sim & sim & & & $\operatorname{sim}$ & $\begin{array}{l}\text { Ser semelhante a } \\
\text { um dos } \\
\text { abecedános } \\
\text { japoneses }\end{array}$ \\
\hline 9 & & sim & $\sin$ & & sim & \\
\hline 10 & $\operatorname{sim}$ & sim & $\sin$ & & sim & \\
\hline 11 & $\operatorname{sim}$ & & $\sin$ & & & \\
\hline 12 & & $\operatorname{sim}$ & $\sin$ & & & \\
\hline 13 & $\operatorname{sim}$ & & $\operatorname{sim}$ & & & \\
\hline 14 & $\operatorname{sim}$ & & $\operatorname{sim}$ & & & \\
\hline 15 & sim & & $\sin$ & & & \\
\hline 16 & & & & & & $\begin{array}{l}\text { Considerar que } \\
\text { entre Árabe e } \\
\text { Russo, Mandarim } \\
\text { é o mais útil }\end{array}$ \\
\hline 17 & & sim & $\sin$ & & & \\
\hline 18 & & & $\sin$ & & & \\
\hline 19 & $\operatorname{sim}$ & & & & sim & \\
\hline 20 & & & $\operatorname{sim}$ & & sim & \\
\hline 21 & & & $\sin$ & sim & sim & \\
\hline 22 & & & $\sin$ & & & \\
\hline 23 & sim & & $\sin$ & & & \\
\hline 24 & & & $\operatorname{sim}$ & & $\operatorname{sim}$ & \\
\hline 25 & $\operatorname{sim}$ & & $\sin$ & & sim & \\
\hline 26 & & & $\operatorname{sim}$ & & & \\
\hline 27 & $\operatorname{sim}$ & & & & & \\
\hline 28 & & & $\sin$ & & $\operatorname{sim}$ & $\begin{array}{l}\text { E uma lingua } \\
\text { complexa e muito } \\
\text { interessante } \\
\text { devido aos } \\
\text { caracteres }\end{array}$ \\
\hline 29 & sim & & & & sim & \\
\hline 30 & & & $\sin$ & & & \\
\hline
\end{tabular}

Fonte: Dados da pesquisa. 
Tabela 2 - Respostas da parte do uso quotidiano do inquérito

\begin{tabular}{|c|c|c|c|c|c|c|}
\hline & $\begin{array}{l}\text { Numa loja } \\
\text { ou } \\
\text { restaurant } \\
\text { e chineses }\end{array}$ & $\begin{array}{l}\text { Ouvir } \\
\text { músice, ver } \\
\text { telenovelas } \\
\text { ou filmes } \\
\text { chineses }\end{array}$ & $\begin{array}{l}\text { Aceder a } \\
\text { mais } \\
\text { informaçöes } \\
\text { na net }\end{array}$ & $\begin{array}{l}\text { Conhecer } \\
\text { mais } \\
\text { pessoas nas } \\
\text { redes } \\
\text { sociais }\end{array}$ & $\begin{array}{l}\text { Comprar } \\
\text { produtos } \\
\text { online na } \\
\text { Chine }\end{array}$ & Outras situạ̧ões \\
\hline 1 & $\operatorname{sim}$ & $\operatorname{sim}$ & & $\operatorname{sim}$ & & \\
\hline 2 & $\operatorname{sim}$ & $\operatorname{sim}$ & & & $\operatorname{sim}$ & \\
\hline 3 & & $\operatorname{sim}$ & $\operatorname{sim}$ & & $\operatorname{sim}$ & \\
\hline 4 & $\operatorname{sim}$ & $\operatorname{sim}$ & & & $\operatorname{sim}$ & \\
\hline 5 & $\operatorname{sim}$ & $\operatorname{sim}$ & & & & $\begin{array}{l}\text { Poder us ar a língua chinesa como } \\
\text { meio de comunicação direta (num } \\
\text { diálogo) }\end{array}$ \\
\hline 8 & $\operatorname{sim}$ & $\operatorname{sim}$ & $\operatorname{sim}$ & & & \\
\hline 7 & $\operatorname{sim}$ & $\operatorname{sim}$ & & $\operatorname{sim}$ & $\operatorname{sim}$ & \\
\hline 8 & $\operatorname{sim}$ & & & & $\operatorname{sim}$ & $\begin{array}{l}\text { Perceber as instruçöes de produtos } \\
\text { disponiveis em outros países }\end{array}$ \\
\hline 9 & $\operatorname{sim}$ & & $\operatorname{sim}$ & $\operatorname{sim}$ & & \\
\hline 10 & $\operatorname{sim}$ & $\operatorname{sim}$ & & $\operatorname{sim}$ & $\operatorname{sim}$ & \\
\hline 11 & $\operatorname{sim}$ & & $\operatorname{sim}$ & & & \\
\hline 12 & & $\operatorname{sim}$ & & & & \\
\hline 13 & $\operatorname{sim}$ & $\operatorname{sim}$ & & & & \\
\hline 14 & & & & & & $\begin{array}{l}\text { Contactar com empres as chines as } \\
\text { quando trabal har }\end{array}$ \\
\hline 15 & $\operatorname{sim}$ & & $\operatorname{sim}$ & & $\operatorname{sim}$ & \\
\hline 16 & $\operatorname{sim}$ & & & & & \\
\hline 17 & $\operatorname{sim}$ & $\operatorname{sim}$ & $\operatorname{sim}$ & & $\operatorname{sim}$ & \\
\hline 18 & & & & & & Emprego futuro \\
\hline 19 & $\operatorname{sim}$ & & & & & \\
\hline 20 & $\operatorname{sim}$ & & & & & \\
\hline 21 & $\operatorname{sim}$ & $\operatorname{sim}$ & & & & \\
\hline 22 & $\operatorname{sim}$ & $\operatorname{sim}$ & $\operatorname{sim}$ & & & \\
\hline 23 & $\operatorname{sim}$ & & $\operatorname{sim}$ & $\operatorname{sim}$ & & \\
\hline 24 & $\operatorname{sim}$ & & & & $\operatorname{sim}$ & Emprego \\
\hline 25 & $\operatorname{sim}$ & $\operatorname{sim}$ & $\operatorname{sim}$ & & $\operatorname{sim}$ & \\
\hline 26 & $\operatorname{sim}$ & & $\operatorname{sim}$ & & $\operatorname{sim}$ & \\
\hline 27 & $\operatorname{sim}$ & & & & & \\
\hline 28 & $\operatorname{sim}$ & & & $\operatorname{sim}$ & $\operatorname{sim}$ & Abordar clientes chineses \\
\hline 29 & & $\operatorname{sim}$ & $\operatorname{sim}$ & & & \\
\hline 30 & sim & $\operatorname{sim}$ & $\operatorname{sim}$ & $\operatorname{sim}$ & $\operatorname{sim}$ & \\
\hline
\end{tabular}

Fonte: Dados da pesquisa. 
Entretanto, também aproveitámos para tentar compreender as ocasiões possíveis em que os estudantes portugueses poderiam utilizar o que aprendem nas aulas do Mandarim mediante a segunda pergunta do questionário: "em que situação considera que poderia usar o Mandarim na sua vida quotidiana?”. As opções disponibilizadas são "numa loja ou restaurante chineses”, “ouvir música, ver telenovelas ou filmes chineses”, "aceder a mais informações na net”, "conhecer mais pessoas nas redes sociais”, “comprar produtos on-line na China”, e "outras situações”, que os inqueridos podem preencher livremente.

De acordo com os resultados apresentados (TABELA 2), a situação mais prática e possível de utilizar a língua chinesa é nas lojas e restaurantes chineses, cuja quantidade é bastante significativa em Portugal. Em 2015, existiam já cerca de 6 mil lojas chinesas em Portugal (NOBRE, 2015). Vinte e cinco estudantes concordam que se poderia utilizar o Mandarim quando fazem compras nas lojas chinesas ou comer nos restaurantes chineses. Entretanto, dezasseis inquiridos consideram que a língua chinesa seria possível de ser utilizada quando ouvem música ou veem filmes e telenovelas chineses.

Entretanto, tomando em consideração o impacto relevante da China hoje em dia, particularmente no âmbito da indústria manufatureira e o desenvolvimento próspero do comércio eletrónico, os produtos chineses capturam a crescente atenção no âmbito global. A compra dos produtos na China por meio da Internet passa a ser, por isso, uma maneira mais conveniente e econômica. Neste contexto, o domínio do Mandarim pode ajudar de certa forma a fazer essas compras on-line. Com respeito ao inquérito, treze entrevistados manifestam a possibilidade do uso do Mandarim nesta situação.

Até em certas situações, o Mandarim pode desempenhar o papel de língua franca no âmbito internacional devido à movimentação extremamente ampla dos produtos chineses. Tal como o entrevistado 8 acrescenta na resposta aberta, uma das abordagens possíveis é compreender as instruções de produtos disponíveis em outros países. Aliás, a aquisição de uma língua nova também disponibiliza novos meios de obtenção de informações e conhecimentos.

Doze entrevistados consideram que a língua chinesa poderia ser usada para aceder a mais informações na net. Todavia, curiosamente, a construção de novas amizades no espaço virtual é considerada pelos entrevistados como a situação menos possível de utilizar o Mandarim na sua vida quotidiana, somente 7 deles afirmaram esta possibilidade. Contudo, à medida que a cooperação e intercâmbio entre Portugal e a China se intensificam nos anos recentes, cada vez mais chineses vêm a Portugal por motivos de emprego, estudo, investimento e turismo e em 2018, o número das visitas trocadas entre os dois países atingiu mais de 300 mil (XI, 2018), ampliando evidentemente as oportunidades de contatar com os falantes nativos do Mandarim.

Neste contexto, como o entrevistado 5 menciona no inquérito, o uso do Mandarim como meio de comunicação dialógica também poderia ser uma situação possível na vida real e isto pode ser um razão possível para explicar o seu uso considerado relativamente menos considerável nas redes sociais pelos inqueridos. Em relação às restantes respostas abertas, quatro entrevistados acrescentam igualmente que o trabalho (no futuro) também pode ser uma situação em que disponibilizaria o uso da língua chinesa, enfatizando, mais uma vez, a relevância desta língua no mercado de trabalho em Portugal. 
Não obstante, na aprendizagem de línguas estrangeiras, os aprendentes mais eficazes estão considerados cientes do uso de estratégias (O’MALLEY \& CHAMOT, 1990), designadamente as técnicas, abordagens ou medidas que utilizam intencionalmente com a finalidade de facilitar a aquisição duma nova língua (ALIAS et al., 2012). Por isso, a última parte do inquérito consiste em duas perguntas, designadamente “qual a estratégia que costuma utilizar para aprender Mandarim?" e "quais são as estratégias que considera mais adequadas à aprendizagem desta língua?”.

Neste caso, partindo da compreensão escrita, compreensão oral e produção oral, oferecemos cinco opções de estratégias possíveis, que são "aprender com o manual”, “ouvir música, ver telenovelas ou filmes", "treinar com falantes nativos", "ler livros em chinês” e "ler notícias e jornais online” e também disponibilizámos um espaço de resposta livre.

À luz dos resultados (TABELA 3), a esmagadora maioria de entrevistados concorda que o manual é uma estratégia prática de aprendizagem do Mandarim e somente dois deles não estão de acordo com esta afirmação. Um terço de entrevistados (10 indivíduos) considera que a aprendizagem do Mandarim pode ser realizada por meio do treino com falantes nativos. Relativamente a ouvir música e ver telenovelas ou filmes em Mandarim, sete entrevistados tratam estas abordagens como estratégias de aprendizagem.

No entanto, ler livros ou jornais e notícias on-line na língua-alvo são efetivamente as estratégias menos preferidas dos estudantes, existindo só respetivamente quatro entrevistados em ambas as opções que concordam com a sua utilidade. No que se refere às respostas abertas, os entrevistados acrescentam estratégias com base na produção escrita que não estão incluídas nas cinco opções disponibilizadas. Três entrevistados mencionam a cópia ou escrita dos caracteres como a sua estratégia mais utilizada e, para além disso, fazer traduções também é considerado por um número idêntico de entrevistados como outra estratégia possível de aprender o Mandarim.

Por certos motivos, os estudantes do Mandarim do nível relativamente inicial podem não se sentir à vontade para falar a língua-alvo diante dos falantes nativos e, neste caso, praticar a compreensão oral de uma forma indireta pode ser uma forma viável, como o entrevistado 5 mencionou na reposta aberta, por meio de simplesmente ouvir os falantes nativos a falar a língua-alvo, sendo outra forma estratégica de aprendizagem. Aliás, a aprendizagem também se pode realizar com recurso às ferramentas, tendo como exemplo, as memory cards referidas pelo entrevistado 28 , que também pode ser uma estratégia eficaz.

Entretanto, pode-se encontrar na resposta do entrevistado 4 outro exemplo evidente, o qual aprende o Mandarim vendo telenovelas ou filmes em Português ou Inglês com legendas em Mandarim, desvendando mais uma possibilidade estratégica de aprendizagem. Não obstante, descobrimos que onze estudantes, o que ocupa mais de um terço da quantidade total dos entrevistados, aprendem o Mandarim somente por meio de manual, desvendando a sua inconsciência do uso de outras estratégias praticáveis na aprendizagem. 
Tabela 3 - Respostas da parte da estratégia do inquérito

$\begin{array}{llllll}\text { Aprender } & \text { Ouvir } & \text { Treinar } & \text { Ler livros } & \text { Ler noticias Outras maneiras } \\ \text { com o } & \text { música, } & \text { com } & \text { em } & \text { e jornais } & \\ \text { manual } & \text { ver } & \text { falantes } & \text { chinês } & \text { online } \\ & \text { telenovelas } & \text { nativos } & & \\ & & & & \end{array}$

ou filmes

\begin{tabular}{|c|c|c|c|c|c|c|}
\hline 1 & $\operatorname{sim}$ & & & & & \\
\hline 2 & sim & & & & & \\
\hline 3 & $\operatorname{sim}$ & $\operatorname{sim}$ & $\operatorname{sim}$ & & & \\
\hline 4 & $\operatorname{sim}$ & & sim & & sim & $\begin{array}{l}\text { Ver telenovelas ou filmes em inglês/português } \\
\text { com legendas em Mandarim }\end{array}$ \\
\hline 5 & sim & sim & & & & Escrever e ouvir pessoas a falar chinês \\
\hline 6 & $\operatorname{sim}$ & & sim & sim & & \\
\hline 7 & $\operatorname{sim}$ & sim & sim & & & \\
\hline 8 & sim & & & sim & & \\
\hline 9 & & $\operatorname{sim}$ & sim & & & \\
\hline 10 & $\operatorname{sim}$ & & & & & Fazer traduçōes \\
\hline 11 & $\operatorname{sim}$ & & & & & \\
\hline 12 & sim & & & & & \\
\hline 13 & $\operatorname{sim}$ & & & & $\operatorname{sim}$ & $\begin{array}{l}\text { Treinar a escrita e as regras gramaticais; } \\
\text { escrever caracteres e os seus significados } \\
\text { várias vezes. }\end{array}$ \\
\hline 14 & $\operatorname{sim}$ & & sim & & & \\
\hline 15 & sim & & sim & & sim & \\
\hline 16 & $\operatorname{sim}$ & & & & & \\
\hline 17 & $\operatorname{sim}$ & sim & & & & \\
\hline 18 & $\operatorname{sim}$ & & sim & & & \\
\hline 19 & $\operatorname{sim}$ & & & & & \\
\hline 20 & sim & & & & & \\
\hline 21 & $\operatorname{sim}$ & $\operatorname{sim}$ & sim & sim & & \\
\hline 22 & sim & & & & $\operatorname{sim}$ & \\
\hline 23 & $\operatorname{sim}$ & & & & & Escrever os caracteres \\
\hline 24 & $\operatorname{sim}$ & & & $\operatorname{sim}$ & & Fazer traduçōes \\
\hline 25 & & & & & & Fazer traduçōes \\
\hline 26 & $\operatorname{sim}$ & & & & & \\
\hline 27 & $\operatorname{sim}$ & & & & & \\
\hline 28 & $\operatorname{sim}$ & sim & sim & & & Memory cards \\
\hline 29 & sim & & & & & \\
\hline 30 & $\operatorname{sim}$ & & & & & \\
\hline
\end{tabular}

Fonte: Dados da pesquisa. 


\section{CONCLUSÃO}

Segundo os resultados do questionário, pode-se dizer que atualmente o Mandarim possui uma importância incontestável em Portugal, cuja necessidade é bastante forte e premente no mercado de trabalho. Mais de metade dos aprendentes decidiram aprender essa língua por razões profissionais. Ademais, o charme da cultura chinesa, a particularidade do Mandarim e o seu sistema linguístico complexo também podem ser razões que explicam a popularidade desta língua oriental em Portugal. Aliás, o possível uso da língua chinesa no dia a dia dos aprendentes portugueses, de facto, não se limita somente no manual, existem diversas outras ocasiões em que os estudantes podem utilizar e treinar a língua-alvo.

E isto é, na verdade, uma consciência que todos os inquiridos têm. Contudo, muitos deles ainda não estão consciente de aplicar estratégias múltiplas ou aproveitar materiais e ferramentas além do manual no processo de aprendizagem. Um bastante número dos estudantes recorre somente ao manual na sua aprendizagem, o qual, de fato, pode não ajudar eficientemente à compreensão sistemática dessa língua. E, com efeito, a sobredependência dos materiais descontextualizados, os focos desequilibrados no input dos conhecimentos e a ignorância do output, designadamente a produção da língua-alvo e a competência comunicativa podem provocar falhas na abordagem da natureza contextualizada da comunicação (LIU; ZHAO, 2008; TEDICK; WALKER, 1995).

Não obstante, sendo um aspeto particular do funcionamento humano, as línguas desempenham o papel de mediar as relações entre os humanos e o mundo (LAFFORD, 2009). Neste contexto, a aprendizagem de línguas deve ser considerada participativa, socialmente constituída e inseparável do contexto social (VYGOTSKY, 1978). Porém, em conformidade com o resultado do questionário, a aprendizagem da língua chinesa limita-se ainda na memorização dos caracteres. Só dez entrevistados reconhecem ou apercebem a importância da natureza social de língua no processo de aprendizagem, afirmando a utilidade da comunicação com os falantes nativos. Se bem que fazer traduções também seja uma estratégia viável durante a aprendizagem, é importante estar consciente da negligência respeitante das competências de compreensão e produção orais que pode existir na prática.

De forma geral, pode-se dizer que neste momento o domínio do Mandarim pode ser essencial e vantajoso para a carreira profissional e facilitar a empregabilidade em Portugal. Contudo, a sua aprendizagem ainda se mantém na memorização passiva no concernente à gramática e caracteres e muitos estudantes omitem a importância do uso da língua-alvo no contexto social. Isto pode causar influências negativas relativamente à aquirição desta língua. À vista disso, será imperativo prestar atenção à criação das capacidades orais no ensino e desenvolver e inovar os materiais didáticos com a intenção de trazer mais possibilidades praticáveis e eficazes aos estudantes.

Assim, como sugestões para futuros estudos, devido considerarmos que os estudantes do primeiro ano ainda não possuíram um conhecimento sistemático e completo relativamente à língua chinesa no momento e, ao mesmo tempo, o planeamento do curso do terceiro ano não permitiu a realização do questionário, o presente estudo focaliza-se somente nos aprendentes do segundo ano. Aliás, os resultados podem ter uma representatividade das opiniões e perspetivas dos alunos da tal etapa de 
aprendizagem. Portanto, espera-se que futuros estudos possam desenvolver uma análise mais global a partir deste ângulo.

Por outro lado, a quantidade dos dados é, de fato, um número relativamente reduzido e os seus resultados podem ter certas limitações. Ademais, acreditamos que os estudantes de diferentes faixas etárias também podem possuir pontos de vistas distintos no que diz respeito ao motivo de aprendizagem e uso de estratégia que será também um aspecto que se pode melhorar e desenvolver em futuras especulações.

\section{REFERÊNCIAS}

ALIAS, A. A.; MANAN, N. A. A.; YUSOF, J.; PANDIAN, A. The use of Facebook as language learning strategy (LLS) training tool on college students' LLS use and academic writing performance.

Procedia - Social and Behavioral Sciences, v. 67, p. 36-48, dez. 2012. Disponível em: https://doi. org/10.1016/j.sbspro.2012.11.305. Acesso em: 11 jan. 2019

CARDOSO, A. I. C. 0 ensino de chinês a crianças: dificuldades e estratégias de ensino. 2014. 54f. Relatório de estágio (Mestrado em Estudos Interculturais Português/Chinês: Tradução, Formação e Comunicação Empresarial) - Instituto de Letras e Ciências Humanas, Universide do Minho, Braga, 2014. Disponível em: http://hdl.handle.net/1822/33084. Acesso em: 11 jan. 2019.

DAI, Q.; MIAO, D. On difficulties of second language teaching. Han Yu Xue Xi, v. 5, p. 96-101, out. 2008. Disponível em: http://www.ixueshu.com/document/905a1d30eedb3545.html. Acesso em: 11 jan. 2019.

HILL, M. M.; HILL, A. A construção de um questionário. S. L.: DINÂMIA, 1998. Disponível em: https:// repositorio.iscte-iul.pt/bitstream/10071/469/4/DINAMIA_WP_1998-11.pdf. Acesso em: 11 jan. 2019.

LAFFORD, B. A. Toward an Ecological CALL: Update to Garrett (1991). The Modern Language Journal, v. 93, n. 1, p. 673-696, dez. 2009. Disponível em: https://doi.org/10.1111/j.15404781.2009.00966.x. Acesso em: 11 jan. 2019.

LIU, Y.; ZHAO, S. Coding the transformation of Chinese pedagogical practices in Singapore primary schools: A study of experiment. The American Educational Research Association (AERA) 2008 Annual Meeting, p. 1-23, mar. 2008. Disponível em: http://hdl.handle.net/10497/3331. Acesso em: 11 jan. 2019.

MAI, R. Ensino de chinês a falantes de português: o caso da Universidade de Aveiro. 2012. $482 \mathrm{f}$. Tese (Doutoramento em Linguística) - Departamento de Línguas e Culturas, Universidade de Aveiro, Aveiro, 2012. Disponível em: http://hdl.handle.net/10773/9842. Acesso em: 11 jan. 2019. 
MENDES, F. R. N. Importância de manuais escolares na aprendizagem de línguas estrangeiras por jovens adultos: o caso do mandarim. 2016. 205f. Dissertação (Mestrado em Estudos Interculturais Português/Chinês: Tradução, Formação e Comunicação Empresarial) - Instituto de Letras e Ciências Humanas, Universide do Minho, Braga, 2014. Disponível em: http://hdl.handle.net/1822/44340. Acesso em: 11 jan. 2019.

MOUTA, I. C. Z. 0 ensino de chinês no ensino básico em São João da Madeira. 2015. 129f. Dissertação (Mestrado em Estudos Chineses) - Departamento de Línguas e Culturas, Universidade de Aveiro, Aveiro, 2015. Disponível em: http://hdl.handle.net/10773/16574. Acesso em: 11 jan. 2019.

NOBRE, A. 1, 2, 3... seis mil lojas do chinês. Economia. jun. 2015. Disponível em: https://expresso. pt/economia/2015-06-14-1-2-3.-seis-mil-lojas-do-chines. Acesso em: 11 jan. 2019.

O’ MALLEY, J. M.; CHAMOT, A. U. Learning Strategies in Second Language Acquisition. Cambridge: Cambridge University Press, 1990.

TEDICK, D. J.; WALKER, C. L. From theory to practice: How do we prepare teachers for second language classrooms? Foreign Language Annals, v. 28, n. 4, p. 499-517, dez. 1995. Disponível em: https://doi.org/10.1111/j.1944-9720.1995.tb00823.x. Acesso em: 11 jan. 2019.

TOVAR, R. S. S. Ensino de chinês: matérias, dificuldades, técnicas e práticas. 2015. 67f. Relatório de estágio (Mestrado em Estudos Interculturais Português/Chinês: Tradução, Formação e Comunicação Empresarial) - Instituto de Letras e Ciências Humanas, Universide do Minho, Braga, 2014.

Disponível em: http://hdl.handle.net/1822/35791. Acesso em: 11 jan. 2019.

TUCKMAN, B. W. Manual de Investigação em Educação. Lisboa: Fundação Calouste Gulbenkian, 2002.

VYGOTSKY, L. Mind in society: The development of higher psychological processes. Cambridge: Harvard University Press, 1978.

WONG, L.; CHAI, S.; AW, G. Seamless language learning: Second language learning with social media. Media Education Research Journal, v. 25, n. 50, p. 9-21, jan. 2017. Disponível em: https:// doi.org/10.3916/C50-2017-01. Acesso em: 11 jan. 2019.

WONG, L.; KING, R. B.; CHAI, C.; LIU, M. Seamlessly learning Chinese: contextual meaning making and vocabulary growth in a seamless Chinese as a second language learning environment.

Instructional Science, v. 44, n. 5, p. 399-422, ago. 2016. Disponível em: https://doi.org/10.1007/ s11251-016-9383-z. Acesso em: 11 jan. 2019. 
$\mathrm{XI}$, J. Uma amizade que transcende o tempo e o espaço, uma parceria voltada para o futuro. Jornal de Notícias, dez. 2018. Disponível em: https://www.jn.pt/nacional/especial/interior/xi-jinping-umaamizade-que-transcende-o-tempo-e-o-espaco-uma-parceria-voltada-para-o-futuro-10268084.html. Acesso em: 11 jan. 2019.

YEN, Y.; HOU, H.; CHANG, K. Applying role-playing strategy to enhance learners' writing and speaking skills in EFL courses using Facebook and Skype as learning tools: a case study in Taiwan. Computer Assisted Language Learning, v. 28, n. 5, p. 383-406, out. 2013. Disponível em: https:// doi.org/10.1080/09588221.2013.839568. Acesso em: 11 jan. 2019. 
2 Atualmente é professor de português como língua estrangeira na Universidade de Línguas Estrangeiras de Dalian e também trabalhou como professor de mandarim como língua estrangeira no Instituto Confúcio da Universidade de Aveiro. Doutoranda em Multimédia da Educação, Universidade de Aveiro, cuja direcção de investigação é a aplicação de ferramentas de redes sociais para aprender mandarim como língua estrangeira. E-mail: yuxiongzhang@ua.pt

3 Doutor em Didática de Línguas Estrangeiras pela Universidade de Aveiro; Professor Associado do Departamento de Educação e Psicologia, Universidade de Aveiro.

E-mail: moreira@ua.pt

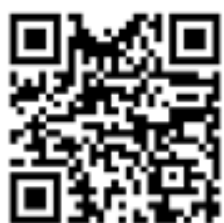

A autenticidade desse artigo pode ser conferida no site https://periodicos. set.edu.br

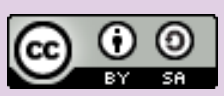

Este artigo é licenciado na modalidade acesso abertosob a Atribuição-Compartilhalgual CC BY-SA

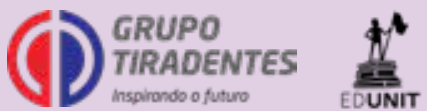

